Témoigner Témoigner. Entre histoire et mémoire

Getuigen Revue pluridisciplinaire de la Fondation Auschwitz

$124 \mid 2017$

La musique dans les camps

\title{
La mémoire revisitée?
}

Éditorial

Wanneer verschillende visies op het herinneringsbeleid botsen met elkaar.

Redactioneel

Frédéric Crahay

\section{OpenEdition}

Journals

Édition électronique

URL : https://journals.openedition.org/temoigner/5633

DOI : 10.4000/temoigner.5633

ISSN : 2506-6390

Éditeur :

Éditions du Centre d'études et de documentation Mémoire d'Auschwitz, Éditions Kimé

Édition imprimée

Date de publication : 2 avril 2017

Pagination : 4

ISBN : 978-2-930953-00-7

ISSN : 2031-4183

Référence électronique

Frédéric Crahay, «La mémoire revisitée ? », Témoigner. Entre histoire et mémoire [En ligne], 124 | 2017, mis en ligne le 30 novembre 2021, consulté le 01 décembre 2021. URL : http://

journals.openedition.org/temoigner/5633; DOI : https://doi.org/10.4000/temoigner.5633 
$\rightarrow$ Par Frédéric Crahay,

Directeur de la rédaction

La mémoire revisitée? e nouveau musée de la Seconde Guerre mondiale (Muzeum II Wojny Światowej) devrait ouvrir ses portes d'ici peu à Gdańsk en Pologne dans la ville où furent tirés le $1^{\text {er }}$ septembre 1939 par le cuirassé allemand Schleswig-Holstein les premiers coups de canon de la Seconde Guerre mondiale. Fruit d'un travail de huit années d'un collectif d'éminents historiens polonais et étrangers, il s'agit du plus grand musée européen (avec un parcours de $6800 \mathrm{~m}^{2}$ ) consacré à la Seconde Guerre mondiale en Europe. Un beau projet entaché de discordes entre le ministère de la Culture représenté par son ministre, le conservateur Piotr Gliński et la direction du musée. Son directeur, l'historien Paweł Machewicz, serait même menacé de licenciement alors que son mandat devait aller jusqu'en 2019. Machewicz, un historien post 1989, voulait une exposition qui parte du point de vue polonais pour entrer dans une vision plus large, plus européenne, et ce, en évitant tant que faire se peut les instrumentalisations politiques. Ce musée « pour les Polonais et les Européens » ne colle pas avec la vision de «nouveau récit national pour la Pologne » appuyé par le parti Droit et Justice - PiS, dont est issu Gliński.

Serait-ce là le signe du retour d'une mémoire dirigée telle que la Pologne l'a connue sous l'ère communiste, mais issue ici d'un gouvernement de droite nationaliste actuellement au pouvoir? Le journaliste du Monde Alain Frachon tire la sonnette d'alarme dans sa chronique du 27 janvier 2017 : «Des générations de jeunes Européens risquent d'être privées d'une expérience pédagogique unique au monde. » De fait, le musée auquel la société belge Tempora a consacré près de huit années de travail ne verra probablement le jour que profondément modifié. Le conflit d'intérêts politique qui se déroule en partie sous les feux des projecteurs est intéressant à plus d'un titre. D'une part, parce que face au ministère de la Culture polonais se dressent des spécialistes renommés de l'histoire de la Shoah ou de sa représentation tels que l'historien américain Timothy Snyder ou le britannique Norman Davies. D'autre part, parce que l'affrontement est politique, Donald Tusk, l'actuel président du Conseil européen d'origine polonaise, ayant jadis lancé l'idée de ce musée en donnant le feu vert à sa conception.

Le réel danger que chaque historien - et plus largement chaque scientifique devrait percevoir est celui de l'incursion du politique et de l'idéologie sur le terrain de la recherche historiographique. Début 2016, le gouvernement polonais actuel s'était déjà illustré en retirant la médaille d'Ordre du mérite à l'historien Jan Tomasz Gross, le jugeant «antipatriote » dans ses écrits. Les musées portent toujours un tant soit peu le reflet du gouvernement qui les met en place. Le musée de Gdańsk n'est pas encore ouvert au public que le gouvernement actuel veut déjà le réorienter. Pire, les médias parlent ici d'une véritable réécriture de l'Histoire. Certains voient même plus loin. Outre une révision historique, nous assistons en effet en direct, en pleine Union européenne, à une démocratie qui se laisse de plus en plus manipuler. Les spectateurs de ce bras de fer dont nous faisons partie, attendent le dénouement du conflit avec une certaine anxiété. Il est important pourtant, une fois de plus, que les revues scientifiques, tout comme les musées et mémoriaux, veillent à garder jalousement leur indépendance intellectuelle. 